\title{
KARYA MONUMENTAL
}

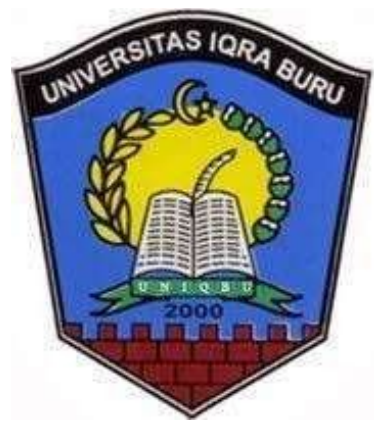

MANFAAT PEMAKAIAN GLASS FIBER REINFORCED POLYMER

(GFRP) PADA KOMPONEN STRUKTUR SALURAN PRACETAK U-DITCH

Oleh

1. Muhammad Tharik Kemal, M.T / NIDN. 1205029001

2. Erwin Syaiful Wagola, S.T., M.T/ NIDN. 1223108501

UNVERSITAS IQRA BURU

FAKULTAS TEKNIK

PROGRAM STUDI TEKNIK SIPIL

2022 
Konsep material yang diperkuat dengan serat sebenarnya telah ditemukan pada penggunaan jerami sebagai penguat dalam batu bata yang diproduksi tahun 800 SM di Israel. Sedangkan di Amerika Serikat, penggunaan penguat serat gelas pendek untuk campuran semen telah dilakukan sejak tahun 1930-an dan material dengan matriks resin yang diperkuat serat (komposit yang kita kenal hari ini) sudah mulai dikembangkan sejak tahun 1940-an. Dalam paper ini, istilah komposit yang digunakan nanti akan merujuk kepada polimer yang diperkuat dengan serat atau biasa disebut dengan FRP (Fiber Reinforced Polymer).

Serat adalah unsur penting dalam komposit. Banyak penelitian dan pengembangan telah dilakukan mengenai efek-efek serat dalam jenis, fraksi volume, desain dan orientasi. Serat umumnya menempati 30\% - 70\% dari volume matriks dalam komposit. Serat dapat dicincang, ditenun, dijahit dan/atau dikepang. Jenis serat yang paling umum digunakan dalam advance fiber reinforced polymer composites untuk aplikasi struktural adalah Glass fiber, aramid, dan karbon. Glass fiber adalah serat yang paling murah, sedangkan karbon adalah yang paling mahal. Harga serat aramid hampir sama dengan harga serat karbon kualitas rendah. Kemudian pada paper ini yang akan dibahas adalah glass fiber.

Glass fiber dibagi menjadi tiga kelas, yaitu E-glass, $S$-glass dan C-glass. $C$ glass ditujukan untuk penggunaan pada aplikasi kelistrikan, S-glass digunakan untuk kekuatan tinggi dan E-glass digunakan untuk ketahanan korosi yang tinggi. Dari ketiga serat tersebut, $E$ glass adalah material penguat yang paling umum digunakan dalam struktur sipil. E-glass terbuat dari lime-alumina-borosilicate yang dapat dengan mudah diperoleh dari kelimpahan bahan baku seperti pasir. Kekuatan dan modulus glass fiber dapat menurun dengan meningkatnya suhu. Oleh karena itu, material glass dapat mengalami creep pada beban berkelanjutan. Glass fiber sendiri dianggap sebagai material isotropik dan memiliki koefisien ekspansi termal yang lebih rendah dibandingkan dengan baja.

Di kota-kota besar di Indonesia saat ini, telah dikembangkan dan diterapkan penggunaan atau pemanfaatan sistem saluran drainase yang berbasis saluran beton pracetak (U-ditch). Namun demikian, setiap tipe atau model saluran beton pracetak (U-ditch) yang diproduksi baik secara mandiri maupun oleh pabrikan lokal di Indonesia, masi berbasis standar dari segi desain masingmasing pabrikan dalam hal ini, model maupun sistem tulangannya masi berbasis pada standar pelayanan yang didesain atau dibuat oleh pabrikan yang memproduksi U-ditch tersebut. Pada Gambar 1 dan Gambar 2 di bawah ini, memperlihatkan salah satu model serta sistem penulangan untuk saluran drainase beton pracetak U-ditch dari salah satu pabrikan lokal di Indonesia. 


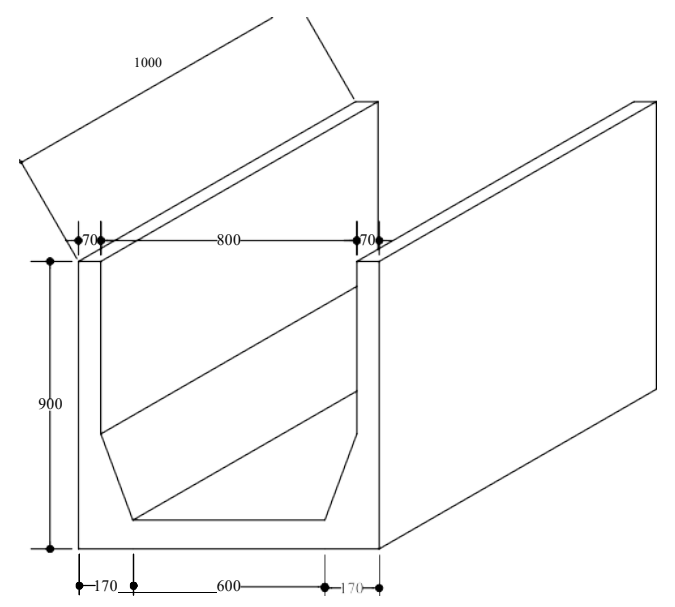

Gambar 1. Tipe Saluran Beton Pracetak U-Ditch

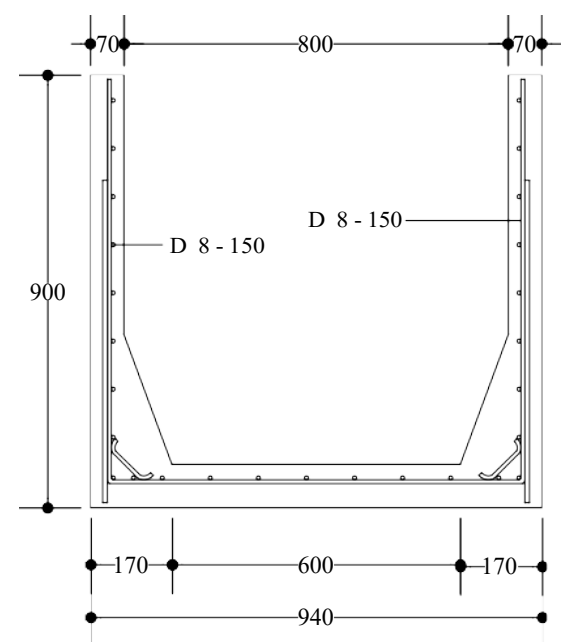

a. Tampak depan

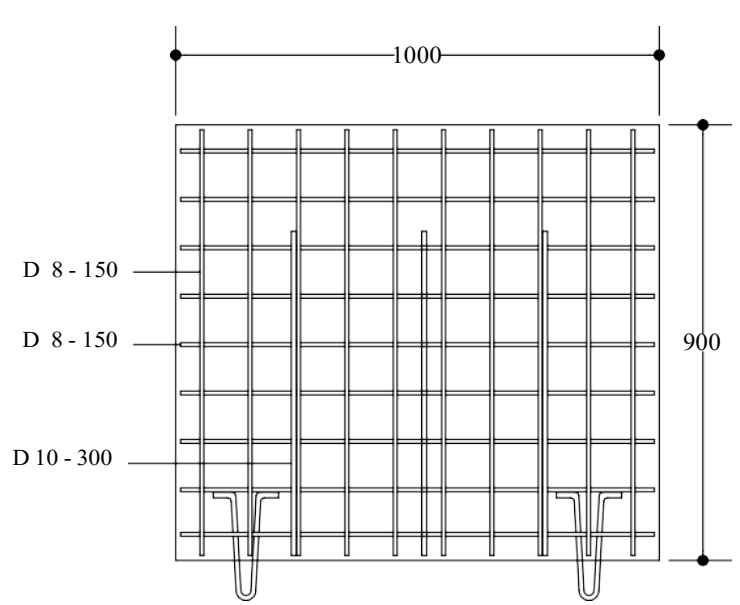

b. Tampak Samping

Gambar 2. Sistem penulangan Beton Pracetak U-Ditch

Dari Gambar 1 dan Gambar 2 di atas, terlihat bahwa model atau tipe saluran drainase beton pracetak (U-ditch) serta sistem penulangannnya masi berbasis pada standar pabrikan dari pada produsen yang memproduksi saluran drainase beton pracetak (U-ditch) tersebut, hal ini dikarenakan belum adanya suatu peraturan yang baku atau standar seperti SNI, yang khusus mengatur tentang saluran drainase beton pracetak, yang selanjutnya dapat dijadikan sebagai acuan oleh setiap produsen atau pabrikan beton pracetak di Indonesia dalam memproduksi saluran drainase beton pracetak. Disamping itu pula, keberadaan saluran drainase pracetak di Indonesia saat ini rata-rata memiliki model atau tipe saluran yang sama, dimana dinding dari pada saluran masi bersifat homogen atau sama antara satu pabrikan dengan pabrikan lainya, olehnya itu sangatlah penting untuk memodifikasi model atau tipe dinding dari pada saluran drainase beton pracetak (U-ditch) yang secara pemodelan tergolong mudah dikerjakan dan secara struktural 
tergolong ringan dan memiliki ketahanan struktur yang baik dalam menahan beban lateral berupa tekanan tanah di dinding saluran.

Saat ini tipe atau model dari pada saluran drainase beton pracetak (U-ditch) yang kami telah dimodifikasi dengan tipe dinding Corrugated atau saluran beton pracetak yang memiliki bagian luar dari dinding saluran tidak datar tetapi agak bergelombang, dimana sebagian dari pada dinding saluran dihilngkan dimana hal ini dimaksudkan agar mengurangi berat struktur namun tidak mengurangi kapsitas atau ketahanan struktur dari pada saluran drainase pracetak tersebut, dan jugamemiliki nilai seni dari segi tampilan strukturnya. Adapun model atau desain dinding Corrugated dari pada saluran beton pracetak yang dimaksud diperlihatkan pada Gambar 3 di bawah ini.

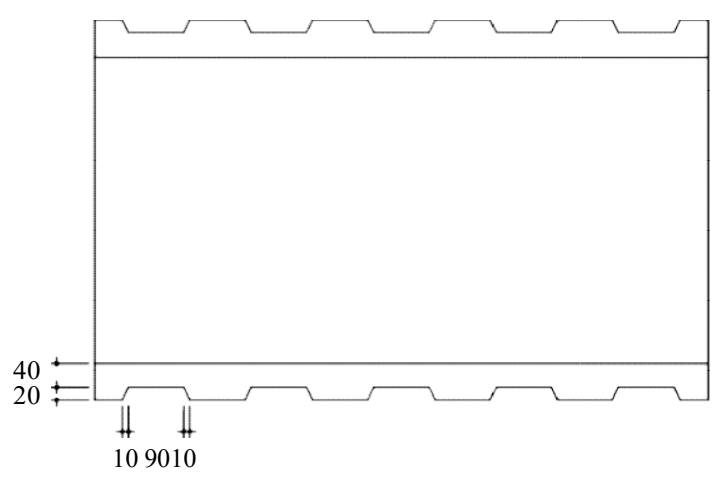

a. Tampak depan

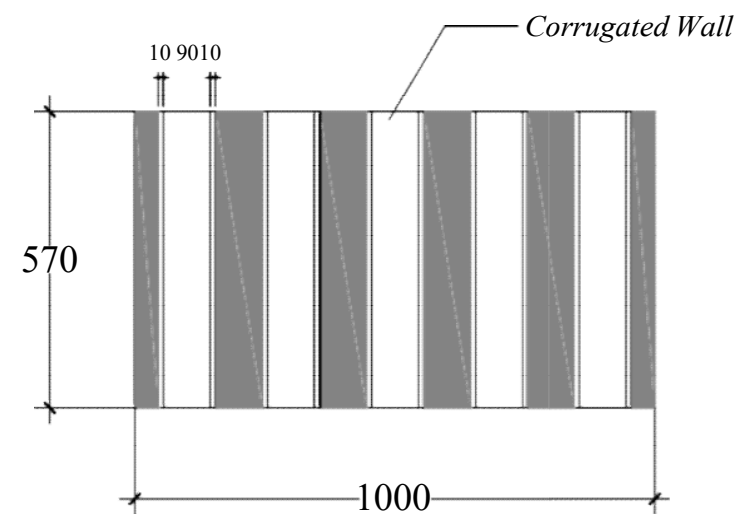

b. Tampak Samping

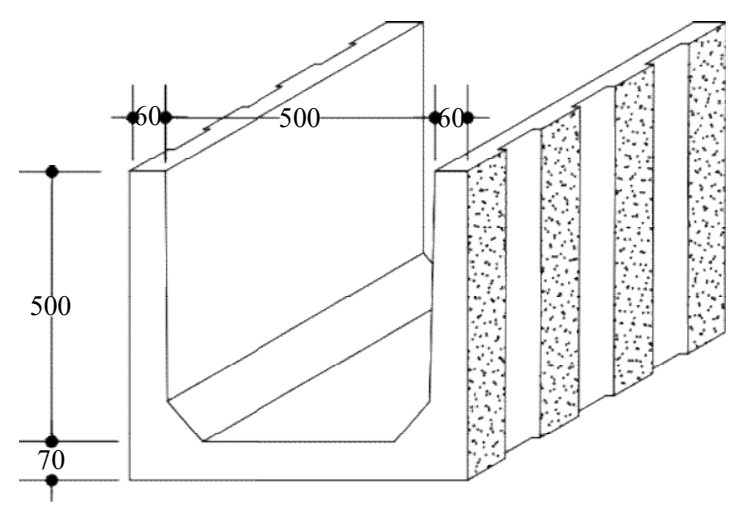

c. Tampak Perspektif

Gambar 3. Desain Pemodelan Saluran Beton Pracetak U-Ditch Type Dinding Corrugated

Dari Gambar 3 di atas tampak suatu konstruksi saluran beton pracetak dengan tampilan dinding yang memiliki nilai inovasi dan seni, namun tetap mempertahankan karakteristik terhadap ketahanan atau kekuatan struktur. 
Beberapa hasil kajian memperlihatkan bahwa konsentrasi beban lentur pada dinding saluran beton pracetak (U-ditch) berada pada 1/3 tinggi saluran dimana daerah ini umumnya paling menderita terhadap pengaruh pembebanan lentur. Hasil penelitian yang dilakukan oleh beberapa ahli ternyata menunjukkan bahwa penerapan pemasangan Glass fiber reinforced polymer (GFRP) pada 1/3 tinggi dinding saluran drainase pracetak U-ditch ternyata mampu menigkatkan kapasitas kuat lentur dari pada dinding saluran beton pracetak (U-ditch) yang dibebabni. Berikut gambar 4 memperlihatkan dinding saluran beton pracetak (U-ditch) yang diperkuat oleh Glass fiber reinforced polymer (GFRP)

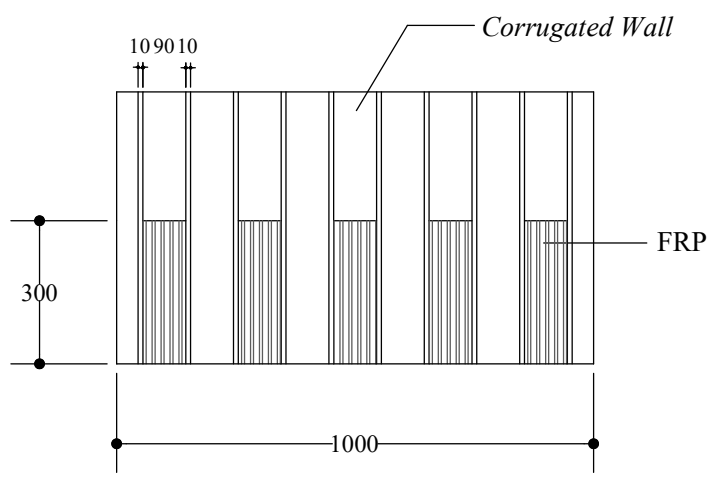

Gambar 4 Saluran Beton Pracetak U-Ditch Type Dinding Corrugated dengan perkuatan GFRP pada 1/3 Tinggi Dinding Saluran 